\title{
Does Providing Assistance to Children and Adolescents Increase Repeatability and Plausibility of Self-Reporting Using a Web-Based Dietary Recall Instrument?
}

\author{
Rossella Murtas, PhD; Vittorio Krogh, MD, MSc; Timm Intemann, Diplom; Lauren Lissner, PhD, MPH; Gabriele Eiben, PhD, RD*; \\ Dénes Molnár, DrSc; Luis A. Moreno, PhD; Alfonso Siani, MD; Michael Tornaritis, PhD; Toomas Veidebaum, PhD; Artur Mazur, MD; \\ Katarzyna Dereń, PhD; Maike Wolters, PhD; Wolfgang Ahrens, Dr rer nat, PhD; Valeria Pala, Dr Sc; on behalf of the I.Family Consortium
}

\section{ARTICLE INFORMATION}

Article history:

Submitted 31 January 2018

Accepted 26 July 2018

\section{Keywords:}

Dietary assessment

Web-based 24-hour recall

Children

Internal validation

External validation

2212-2672/Copyright (C) 2018 by the Academy of Nutrition and Dietetics.

https://doi.org/10.1016/j.jand.2018.07.017

"Certified in Sweden.

\section{ABSTRACT}

Background It is important to find ways to minimize errors when children self-report food consumption.

Objective The objective of this study was to investigate whether assistance given to children completing a self-administered 24-hour dietary recall instrument called SACANA (Self-Administered Child, Adolescent and Adult Nutrition Assessment) increased the repeatability and plausibility of energy intake (EI) estimates.

Participants/setting The study was conducted between October 2013 and March 2016 in a convenience sample of 395 children, aged 8 to 17 years, from eight European countries participating in the I.Family study.

Design SACANA was used to recall the previous day's food intake, twice in a day, once with and once without assistance.

Main outcome measures The difference in EI between the first and second recalls was the main repeatability measure; the ratio of EI to basal metabolic rate was the plausibility measure.

Statistical methods Generalized linear mixed models, adjusted for sex, age, and body mass index $z$-score, were used to assess whether assistance during the first vs second recall influenced repeatability and plausibility.

Results The difference in estimated EI (EI from second recall minus EI from first recall) was significantly lower $(P<0.001)$ in those assisted at first (median $=-76 \mathrm{kcal})$ than those assisted at second recall (median $=282 \mathrm{kcal}$ ). Modeling showed that EI at assisted first recall was $19 \%$ higher ( $95 \%$ CI 1.13 to 1.24 ) than in assisted second recall. Overall, $60 \%$ of recalls had a plausible EI. Modeling to estimate the simultaneous effects of second vs first recall and assistance vs no assistance on plausibility showed that those assisted at first recall had significantly higher odds of a plausible recall than those unassisted (odds ratio 3.64, 95\% CI 2.20 to 6.01), with no significant difference in plausibility of second recall compared to the first (odds ratio $1.48,95 \% \mathrm{CI} 0.92$ to 2.35 ). Conclusions When children are assisted at first recall, the plausibility and repeatability of the later unassisted recall improve. This improvement was evident for all ages. A future, adequately powered study is required to investigate the age range for which assistance is advisable.

J Acad Nutr Diet. 2018,
$\mathrm{D}$ IETARY ASSESSMENT IN LARGE-SCALE EPIDEMIOlogic studies of children is moving toward the use of repeated administration of quantitative 24-hour dietary recall (24hdr) instruments. ${ }^{1}$ Because only shortterm recall is required and the effort required to complete the instrument is limited, ${ }^{2,3} 24 \mathrm{hdrs}$ yield more valid data in children than other methods. ${ }^{1}$ Various $24 \mathrm{hdr}$ dietary assessment instruments have been developed and tested in several countries. ${ }^{4-8}$ However, no one method of dietary assessment is optimal for children of all ages, ${ }^{2,9}$ and consistent recommendations on the earliest age at which children can be relied upon to accurately report a full day's food consumption are not available., ${ }^{2,4}$

One way of overcoming the problem of recall in children is to use proxy reports from parents or caregivers. The European Food Consumption Validation Project to determine how best to perform dietary assessment across Europe ${ }^{2}$ suggested that for schoolchildren (aged 7 to 14 years) a parent/caregiver 


\section{RESEARCH}

should assist the child so as to complement information obtained from the child.

However, parents may not be confident reporting on meals for which they have no direct knowledge. ${ }^{10}$ Furthermore, parental knowledge of foods eaten by their children is associated with family characteristics (eg, number of shared meals) that are not independent of dietary quality, ${ }^{11,12}$ so parental involvement may introduce bias. Although automated web-based instruments may be easier to use than those that are not web-based or computerized, ${ }^{13}$ variable prior experience in using a computer can bias results. Thus a recently published review of experience with an online 24hdr advised that children aged 10 to 13 years should complete the initial recall assisted by a researcher. ${ }^{10}$

As part of the I.Family study-that from 2012 to 2017 investigated determinants of food choices, lifestyle and health in European children and their parents ${ }^{14}-\mathrm{a}$ webbased self-administered 24hdr called SACANA (SelfAdministered Child, Adolescent and Adult Nutrition Assessment $)^{15}$ was developed. The aim of the present study was to investigate whether assistance given to children while self-administering SACANA increased the repeatability and plausibility of estimates of energy intake (EI) derived from the completed recall. Children recalled their previous day's food intake using SACANA twice in 1 day, once with the assistance of a dietitian/interviewer, and once without assistance. It was hypothesized that assistance at first recall would improve performance at the second unassisted recall.

\section{MATERIALS AND METHODS}

\section{Participants}

The study was conducted between October 2013 and March 2016 in a convenience sample of children from seven of the eight centers enrolled in the I.Family study from the following countries: Cyprus, Estonia, Germany, Hungary, Italy, Spain, and Sweden. The Polish center of Rzeszow, which joined I.Family later, was also included. A minimum of 50 children per center, of both sexes, aged 8 to 17 years, was identified by each center as agreeing to recall their diet twice in 1 day. Sample size was calculated based on an expected effect size of a $20 \%$ increase in EI due to assistance.

Of 423 children who agreed, 19 were excluded because recalls were missing (one missed both recalls, six missed the first recall, and 12 missed the second recall) and an additional nine children were excluded because estimated EI was at either extreme of the distribution (cutoffs first and last halfpercentiles) from the first recall (four children), second recall (four children), or both (one child). Mean time between the two recalls was 106 minutes (median $=99$ minutes). Because anthropometric measures were missing for 26 children, the models that evaluated EI plausibility involved only 369 children.

Parents or legal guardians of the participating children gave written informed consent for data collection, examinations, collection of biological samples, and analysis and storage of personal data and samples. In addition, each child gave oral consent after being informed orally (from a simplified text) about the study by a nurse immediately before every examination. This procedure was chosen due to the young age of the children. The oral consent process was subject to quality control.

\section{RESEARCH SNAPSHOT}

Research Question: Does providing assistance for children when they first complete a self-administered 24-hour dietary recall instrument improve the plausibility and repeatability of future completions?

Key Findings: When children are assisted at initial compilation, subsequent independent completion is characterized by improved plausibility and repeatability of the energy intake estimates derived from the instrument.

Study participants and their parents/guardians could consent to individual study components while abstaining from others. Ethical approval was obtained from the relevant local or national ethics committees by all study centers.

\section{From SACINA to SACANA}

SACANA was developed from a computer-based (offline) instrument called SACINA (Self-Administered Children and Infant Nutrition Assessment) ${ }^{16}$ validated in preschool-aged children who had been used (usually by parents) to report their children's food intake in the multicenter study known as Identification and Prevention of Dietary- and LifestyleInduced Health Effects in Children and Infants (IDEFICS). ${ }^{17}$

SACANA development was driven by the need to create an instrument that could be self-completed by children (as well as adolescents and adults). Development involved the creation of a more intuitive graphic interface with many new components, including multiple food images with a variety of portion sizes. ${ }^{15}$ The list of foods included in SACANA was derived from SACINA food lists and was updated for all countries during the SACANA pilot phase. Many foods were country-specific. In IDEFICS, SACINA was used to estimate energy and nutrient intakes ${ }^{18,19}$ and also factors associated with parental misreporting of their children's dietary intake. ${ }^{20}$ The main factors influencing misreporting were low socioeconomic status, high child body mass index (BMI), high parental BMI, mother vs father as proxy reporter, and high parental concern about child's weight status. ${ }^{20}$

\section{Dietary Assessment with SACANA}

Participants use SACANA to enter the types and amounts of foods and drinks consumed at each food consumption occasion (including snacks) over the 24 hours from waking on the preceding day to waking on the day of recall. Choice of one item usually leads to further choices; for example, choosing milk prompts milks of different fat contents, one of which is chosen. If a food usually consumed at a meal is not chosen, it is prompted and the participant has to choose yes vs no. In the case of yes, portion size is displayed and has to be chosen. Typically breakfast is chosen first and a list of countryspecific items commonly consumed at breakfast is presented.

SACANA contains a total of 3,570 food items, some of which are common to some or all countries, others of which are available (presented as choices) only for some countries. All food items present in the food lists have been classified into 145 food groups characterized by common ingredients to render possible analyses of associations of food-group consumption with behavior and health. Food composition tables 
(FCTs) are incorporated into SACANA. These were constructed from country-specific FCTs translated into English and harmonized across countries by adopting procedures to prevent and minimize bias. ${ }^{21}$ Dietary supplements are not assessed by SACANA. Supplement use was recorded in a health and medical history questionnaire administered to a parent/guardian. ${ }^{14}$ Mean times to complete SACANA were 30 minutes for first recall and about 20 minutes for second recall.

\section{Energy Assessment Crossover Experiment}

The participating children recalled their diet using SACANA twice in one day, once assisted and once unassisted. In the unassisted recall, the child entered foods following the onscreen instructions and illustrations. In the assisted recall, the child followed the onscreen instructions, but the dietitian either made the entries or checked that the child did so correctly. The assisted and unassisted recalls were conducted in random order, not less than 1 hour and not more than 4 hours apart, with no meals in between. In both recalls, the child was allowed to ask a parent or study personnel in the case that there was anything he or she did not understand (eg, in the case that the child did not understand the difference between low-fat and full-fat yogurt it would be explained). The children were randomized either to Group 1 in which the first recall was assisted, or to Group 2 in which the second recall was assisted. EI (in kilocalories) was estimated for the first $\left(\mathrm{EI}_{1}\right)$ and the second $\left(\mathrm{EI}_{2}\right)$ recalls, by linking recalled foods to the FCT. ${ }^{21}$ EIs estimated from assisted recalls are denoted $\mathrm{EI}_{\mathrm{a}}$. Those from unassisted recalls are $\mathrm{EI}_{\mathrm{u}}$.

\section{Anthropometry}

Anthropometric measurements were taken serially in the I.Family study using a standard protocol. Only the most recent set of anthropometric measurements was used in the present study. Height was measured to the nearest $0.1 \mathrm{~cm}$ with a stadiometer; body weight was measured with a BC418MA instrument (Tanita Europe $\mathrm{GmbH}$, Sindelfingen, Germany) in light underwear to the nearest $0.1 \mathrm{~kg}$. BMI was weight (in kilograms) divided by height squared (in squared meters). Basal metabolic rate (BMR) was calculated from the Schofield equations. ${ }^{22}$ BMI was transformed to an age- and sex-specific $z$-score according to Cole and colleagues. ${ }^{23}$

\section{Statistical Methods}

Repeatability was assessed by calculating Spearman correlation coefficient $(r)$ between the EI estimates at first and second recalls, and by assessing the difference in EI between the two recalls $\left(\mathrm{EI}_{2}-\mathrm{EI}_{1}\right)$. Spearman $r$ was interpreted according to Serra-Majem criteria. ${ }^{24}$ The normality of distributions $\left(\mathrm{EI}_{1}, \mathrm{EI}_{2}\right.$, and $\left.\mathrm{EI}_{2}-\mathrm{EI}_{1}\right)$ was assessed using skewness and kurtosis tests. ${ }^{25}$ The data were not normally distributed, so the nonparametric Mann-Whitney $U$ test $^{26,27}$ was used to test the significance of differences.

Generalized linear mixed models, with EI as continuous response variable, were used to assess whether EI differed between the first and second recall, and to assess whether assistance during the first vs assistance at the second recall influenced EI estimates. A linear mixed model was run first, but because the distributions of residuals were not normal and also right-skewed, a model with a gamma distribution and logarithmic link function was used:

$$
\begin{aligned}
& \ln \left[\mathrm{E}\left(\mathrm{EI}_{i j}\right)\right]=u_{0 j}+\beta_{1} \text { recall }_{2} \text { s recall } 1_{i j} \\
& +\beta_{2} \text { assisted vs unassisted }_{i j}
\end{aligned}
$$

Equation 1

where $\mathrm{EI}_{i j}$ is the energy intake estimated for child $j$ $(j=1, \ldots, 395)$ at the $i$-th recall $(i=1$ or 2$)$. The parameter $u_{0 j}$ is the individual-specific random intercept, assumed to be normally distributed with zero mean and variance $\Sigma$. The fixed effect recall 2 vs recall 1 is defined as 1 if the $i$-th recall of child $j$ is the second recall, and 0 if the $i$-th recall of child $j$ is the first recall. The fixed effect assisted vs unassisted is defined as 1 if child $j$ was assisted at the $i$-th recall and 0 if the child $j$ was not assisted at the $i$-th recall. The exponential of coefficient $\beta_{1}\left(\exp \left[\beta_{1}\right]\right)$ estimates the effect of the second vs first recall on EI. The exponential of coefficient $\beta_{2}\left(\exp \left[\beta_{2}\right]\right)$ estimates the effect of assistance vs nonassistance on EI.

EI estimates were classified as low, plausible, or high by calculating EI:BMR ratios and comparing them with expected sex- and age-specific EI:BMR ratios for children, using Goldberg cutoffs ${ }^{28}$ modified from those used for adults as suggested by Lioret and colleagues ${ }^{29}$ and Sichert-Heller and colleagues. ${ }^{30}$ Details of this procedure are available elsewhere. ${ }^{20}$

Recalls with plausible and implausibly high Els were combined because only four of 738 recalls had implausibly high EI. Factors associated with being a plausible or implausible reporter were investigated using a generalized linear mixed model (Equation 2). These factors were related to the dichotomized EI:BMR response variable $Y$ via a logit link function. The distribution of the response variable was assumed to be binomial:

$$
\begin{aligned}
& \operatorname{logit}\left[E\left(Y_{i j}\right)\right]=u_{0 j}+\gamma_{1} \text { recall2 vs recall } 1_{i j}
\end{aligned}
$$

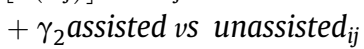

Equation 2

where the exponential of coefficient $\gamma_{1}, \exp \left(\gamma_{1}\right)$ is interpretable as an odds ratio. The odds of being a plausible reporter of EI at the second recall compared with the first. The exponential of coefficient $\gamma_{2}, \exp \left(\gamma_{2}\right)$ is also interpretable as an odds ratio: the odds of being a plausible reporter of EI when assisted compared with being unassisted (at a given recall). Both models (Equation 1 and Equation 2) were adjusted for sex, age, and BMI $z$-score. The latter model (Equation 2) was also run without adjustment.

Significance levels were adjusted using the Bonferroni-Holm correction for multiple testing. ${ }^{31}$ The significance level was set at $\alpha<.05$. The analyses were performed using Stata version 14.0..$^{32}$

\section{RESULTS}

Dietary intake (1 day) stratified by age and sex is shown in Table 1. Mean EI was 1,653 kcal/day in boys and 1,443 kcal/ day in girls. EI repeatability, as assessed by Spearman $r$, was $r=0.69(P<0.001)$ for Group 1 (children assisted at first recall) and $r=0.59(P<0.001)$ for Group 2 (children assisted at second recall). Spearman $r$ was better for girls both in Group 1 (girls $r=0.71[P<0.001]$ vs boys $r=0.64[P<0.001]$ ) and Group 2 (girls $r=0.65[P<0.001]$ vs boys $r=0.54 \quad[P<0.001]$ ). 
Table 1. Daily dietary intake ${ }^{a}$ of participants ${ }^{b}$ as estimated by a self-administered child, adolescent, and adult nutrition assessment (SACANA), by sex and age group Boys

Girls

\begin{tabular}{|c|c|c|c|c|c|c|c|c|c|c|c|c|c|c|c|c|}
\hline \multirow[b]{2}{*}{$\begin{array}{l}\text { Age } \\
\text { group (y) }\end{array}$} & \multicolumn{8}{|c|}{$00 y^{2}$} & \\
\hline & $n$ & $\begin{array}{l}\text { Body } \\
\text { mass } \\
\text { index } \\
\text { z-score }^{c}\end{array}$ & $\begin{array}{l}\text { Food } \\
\text { energy } \\
\text { (kcal/d) }\end{array}$ & $\begin{array}{l}\text { Food } \\
\text { quantity } \\
\text { (g/d) }\end{array}$ & $\begin{array}{l}\text { Protein } \\
(\mathrm{g} / \mathrm{d})\end{array}$ & Fat $(g / d)$ & $\begin{array}{l}\text { Carbohydrate } \\
(\mathrm{g} / \mathrm{d})\end{array}$ & $\begin{array}{l}\text { Sugars } \\
\text { (g/d) }\end{array}$ & $\mathbf{n}$ & $\begin{array}{l}\text { Body } \\
\text { mass } \\
\text { index } \\
\text { z-score }\end{array}$ & $\begin{array}{l}\text { Food } \\
\text { energy } \\
\text { (kcal/d) }\end{array}$ & $\begin{array}{l}\text { Food } \\
\text { quantity } \\
\text { (g/d) }\end{array}$ & $\begin{array}{l}\text { Protein } \\
\text { (g/d) }\end{array}$ & $\begin{array}{l}\text { Fat } \\
(g / d)\end{array}$ & $\begin{array}{l}\text { Carbohydrate } \\
\text { (g/d) }\end{array}$ & $\begin{array}{l}\text { Sugars } \\
(\mathrm{g} / \mathrm{d})\end{array}$ \\
\hline $8-9$ & 2 & 1.85 & 1,528 & 1,366 & 53 & 60 & 202 & 63 & 7 & -0.02 & 1,646 & 1,710 & 66 & 70 & 185 & 52 \\
\hline 10 & 22 & 0.99 & 1,364 & 1,430 & 54 & 46 & 183 & 55 & 26 & 0.74 & 1,316 & 1,524 & 48 & 48 & 172 & 58 \\
\hline 11 & 29 & 0.91 & 1,551 & 1,744 & 63 & 54 & 199 & 78 & 33 & 0.41 & 1,443 & 1,534 & 50 & 58 & 178 & 74 \\
\hline 12 & 33 & 1.00 & 1,651 & 1,692 & 69 & 65 & 193 & 72 & 42 & 0.71 & 1,349 & 1,426 & 49 & 47 & 179 & 64 \\
\hline 13 & 57 & 0.73 & 1,638 & 1,898 & 67 & 56 & 213 & 91 & 61 & 0.46 & 1,525 & 1,577 & 59 & 60 & 185 & 71 \\
\hline $14-17$ & 42 & 0.62 & 1,901 & 1,800 & 72 & 77 & 229 & 80 & 41 & 0.76 & 1,465 & 1,550 & 58 & 59 & 176 & 62 \\
\hline All & 185 & 0.82 & 1,653 & 1,753 & 66 & 61 & 207 & 78 & 210 & 0.58 & 1,443 & 1,533 & 54 & 56 & 179 & 66 \\
\hline
\end{tabular}

Daily intake estimated as mean of first and second SACANA recalls.

DParticipants are a convenience sample of 395 children, aged 8 to 17 years, from eight European countries participating in the I.Family study.

Age- and sex-specific $z$-scores of body mass index were calculated according to Cole and Lobstein ${ }^{23}$ for 369 children with height and weight measurement available.

Table 2. Difference between daily energy intake (El) estimated from second recall $\left(\mathrm{El}_{2}\right)$ and first recall (EI ${ }_{1}$ ) (measure of repeatability) according to whether the first (Group 1) or second (Group 2) recall was assisted

Group 1

First Recall Assisted, Second Unassisted

All Children

\begin{tabular}{|c|c|c|c|c|c|c|c|c|c|c|c|c|}
\hline \multirow[b]{2}{*}{ Variable } & \multicolumn{4}{|c|}{ All Children } & \multicolumn{4}{|c|}{$(n=202 ; 51 \%)$} & \multicolumn{4}{|c|}{$(n=193 ; 49 \%)$} \\
\hline & $\begin{array}{l}\text { Mean } \\
\text { (kcal) }\end{array}$ & $\begin{array}{l}\text { Standard } \\
\text { deviation } \\
\text { (kcal) }\end{array}$ & $\begin{array}{l}\text { Median } \\
\text { (kcal) }\end{array}$ & $\begin{array}{l}\mathrm{IQR}^{\mathrm{a}} \\
\text { (kcal) }\end{array}$ & $\begin{array}{l}\text { Mean } \\
\text { (kcal) }\end{array}$ & $\begin{array}{l}\text { Standard } \\
\text { deviation } \\
\text { (kcal) }\end{array}$ & $\begin{array}{l}\text { Median } \\
\text { (kcal) }\end{array}$ & $\begin{array}{l}\mathrm{IQR}^{\mathrm{a}} \\
\text { (kcal) }\end{array}$ & $\begin{array}{l}\text { Mean } \\
\text { (kcal) }\end{array}$ & $\begin{array}{l}\text { Standard } \\
\text { deviation } \\
\text { (kcal) }\end{array}$ & $\begin{array}{l}\text { Median } \\
\text { (kcal) }\end{array}$ & $\begin{array}{l}\mathrm{IQR}^{\mathrm{a}} \\
\text { (kcal) }\end{array}$ \\
\hline $\mathrm{El}_{1}$ & 1,476 & 711 & 1,398 & 974 to 1,883 & 1,651 & 695 & 1,586 & 1,200 to 1,985 & 1,292 & 682 & 1,195 & 797 to 1,688 \\
\hline $\mathrm{El}_{2}$ & 1,607 & 696 & 1,502 & 1,089 to 1,946 & 1,544 & 689 & 1,450 & 1,056 to 1,856 & 1,673 & 700 & 1,550 & 1,165 to 1,991 \\
\hline $\mathrm{El}_{2}-\mathrm{El}_{1}$ & 132 & 629 & 12 & -164 to 365 & -106 & 504 & $-76^{* * *}$ & -342 to 76 & 380 & 652 & $282^{* * *}$ & 0 to 693 \\
\hline
\end{tabular}

$\mathrm{Q} \mathrm{QR}=$ Interquartile range (25th and 75 th percentiles of distribution).

${ }^{* * *} P<0.001$ for between-group difference (nonparametric Mann-Whitney $U$ test).

Group 2

First Recall Unassisted, Second Assisted $(n=193 ; 49 \%)$ 
Table 3. Differences between daily energy intake (EI) estimated from second recall $\left(\mathrm{EI}_{2}\right)$ and first recall $\left(\mathrm{El}_{1}\right)$ (measure of repeatability) according sex, age class, and whether first (Group 1) or second (Group 2) recall was assisted

Group 1

First Recall Assisted, Second Unassisted $(n=202 ; 51 \%)$

\begin{tabular}{|c|c|c|c|c|c|c|c|}
\hline \multirow[b]{3}{*}{ Variable } & \multicolumn{3}{|c|}{$(n=202 ; 51 \%)$} & \multicolumn{3}{|c|}{$(n=193 ; 49 \%)$} & \multirow[b]{3}{*}{$P$ value } \\
\hline & \multirow[b]{2}{*}{$\mathbf{n}$} & \multicolumn{2}{|c|}{$\mathrm{El}_{2}-\mathrm{El}_{1}$} & \multirow[b]{2}{*}{$\mathbf{n}$} & \multicolumn{2}{|c|}{$\mathrm{El}_{2}-\mathrm{El}_{1}$} & \\
\hline & & Median (kcal) & $\mathrm{IQR}^{\mathrm{a}}$ (kcal) & & Median (kcal) & IQR $^{\mathrm{a}}$ (kcal) & \\
\hline \multicolumn{8}{|l|}{ Sex } \\
\hline Male & 89 & -87 & -422 to 10 & 96 & 318 & -7 to 812 & $<0.001$ \\
\hline Female & 113 & -61 & -248 to 119 & 97 & 236 & 0 to 616 & $<0.001$ \\
\hline \multicolumn{8}{|c|}{ Age class (y) } \\
\hline $8-9$ & 5 & -83 & -211 to 0 & 4 & 267 & -485 to 704 & 0.294 \\
\hline 10 & 17 & -83 & -587 to 0 & 31 & 213 & 0 to 481 & $<0.001$ \\
\hline 11 & 34 & -123 & -489 to 0 & 28 & 247 & -28 to 768 & 0.002 \\
\hline 12 & 38 & -112 & -386 to 19 & 37 & 253 & 51 to 886 & $<0.001$ \\
\hline 13 & 65 & -32 & -232 to 203 & 53 & 388 & 132 to 769 & $<0.001$ \\
\hline $14-17$ & 43 & -65 & -317 to 11 & 40 & 192 & -13 to 385 & 0.001 \\
\hline All & 202 & -76 & -342 to 76 & 193 & 282 & 0 to 693 & $<0.001$ \\
\hline
\end{tabular}

$\mathrm{I} \mathrm{QR}=$ Interquartile range (25th and 75 th percentiles of distribution)

${ }^{b} P$ values for between-group differences in median $\mathrm{El}_{2}-\mathrm{El}_{1}$ (nonparametric Mann-Whitney $U$ test)

Group 2

First Recall Unassisted, Second Assisted

$(n=193 ; 49 \%)$

(1) 


\section{RESEARCH}

Table 5. Odds ratios (ORs) ${ }^{a}$ and $95 \%$ Cls of participants ${ }^{b}$ reporting plausible ${ }^{c}$ energy intake at first self-administered child, adolescent, and adult nutrition assessment (SACANA) recall vs second, and at assisted SACANA recall vs unassisted

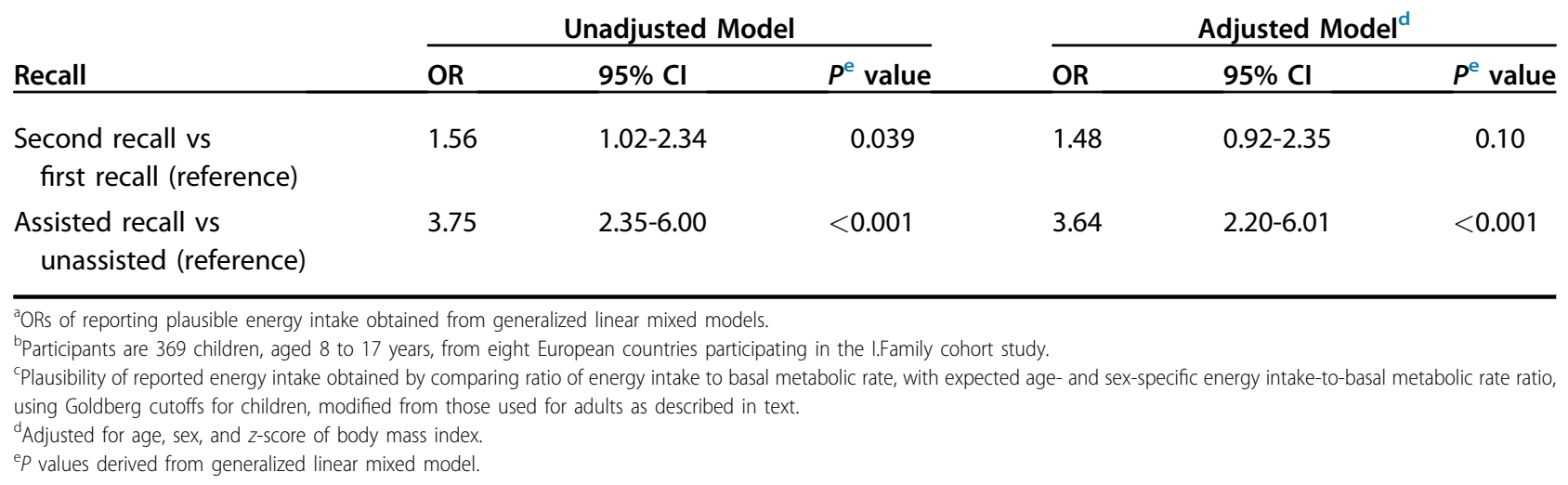

found that children's ability to complete self-administered dietary increases with age. ${ }^{4,9,10}$

Regarding the plausibility of EI estimates, it was found that almost $40 \%$ of EI estimates were implausibly low. This high proportion was expected because underreporting is a known characteristic of $24 \mathrm{hdr}$ instruments. ${ }^{1,33}$ Because the recalls took place on 1 day only, a single day of intake has a wider distribution than does usual intake, with more respondents in the distribution tails. ${ }^{3}$ The validity of self-reported SACANA in measuring to sugar intake was investigated in recent article. $^{34}$ The present study did not validate SACANA, but assessed the repeatability and plausibility of recall. Other variables (eg, water content of diet) were not investigated. However, most important nutrients (eg, macronutrients, most minerals, and B vitamins) have been shown to correlate with EI, and EI is widely accepted as a surrogate measure of recall completeness. ${ }^{33}$

A study limitation is that repeatability was only assessed for recalls 1 to 4 hours later. Because a gold standard measure of dietary intake is not available, the possibility of overestimation of repeatability due to a memory effect cannot be excluded. Another limitation lies in the fact a convenience sample of children (and parents) who agreed to participate was studied, and not enough children in different age classes were recruited to have the power investigate the effect of age on recall repeatability and plausibility.

\section{CONCLUSIONS}

We found that when children are assisted with the initial compilation of a web-based $24 \mathrm{hdr}$, subsequent independent completion is more likely to be plausible and repeatability improves. A future, adequately powered study is required to investigate the age range for which assistance is advisable.

\section{References}

1. Burrows TL, Martin RJ, Collins CE. A systematic review of the validity of dietary assessment methods in children when compared with the method of doubly labeled water. J Am Diet Assoc. 2010;110(10): $1501-1510$.
2. Andersen LF, Lioret S, Brants $\mathrm{H}$, et al. Recommendations for a transEuropean dietary assessment method in children between 4 and 14 years. Eur J Clin Nutr. 2011;65(suppl 1):S58-S64.

3. Thompson F, Subar A. Dietary assessment methodology. In: Nutrition in the Prevention and Treatment of Disease. 4th ed. New York, NY: Elsevier; 2017.

4. Foster E, Hawkins A, Delve J, Adamson AJ. Reducing the cost of dietary assessment: Self-completed recall and analysis of nutrition for use with children (SCRAN24). J Hum Nutr Diet. 2014;27(suppl 1):26-35.

5. Davies VF, Kupek E, de Assis MA, Natal S, Di Pietro PF, Baranowski T. Validation of a web-based questionnaire to assess the dietary intake of Brazilian children aged 7-10 years. J Hum Nutr Diet. 2015;28(suppl 1):93-102.

6. Carvalho MA, Baranowski T, Foster E, et al. Validation of the Portuguese self-administered computerised 24-hour dietary recall among second-, third- and fourth-grade children. J Hum Nutr Diet. 2015;28(6):666-674.

7. Simons-Morton BG, Baranowski T, Parcel GS, O'Hara NM, Matteson RC. Children's frequency of consumption of foods high in fat and sodium. Am J Prev Med. 1990;6(4):218-227.

8. Klesges RC, Klesges LM, Brown G, Frank GC. Validation of the 24hour dietary recall in preschool children. J Am Diet Assoc. 1987;87(10):1383-1385.

9. Adamson AJ, Baranowski T. Developing technological solutions for dietary assessment in children and young people. J Hum Nutr Diet. 2014;27:1-4.

10. Kirkpatrick SI, Gilsing AM, Hobin E, et al. Lessons from studies to evaluate an online 24-hour recall for use with children and adults in Canada. Nutrients. 2017;9(2). pii: E100, https://doi.org/10.3390/nu9020100.

11. Hebestreit A, Intemann T, Siani A, et al. Dietary patterns of European children and their parents in association with family food environment: Results from the I.Family study. Nutrients. 2017;9(2). pii: E126, https://doi.org/10.3390/nu9020126.

12. Valdés J, Rodríguez-Artalejo F, Aguilar L, Jaén-Casquero MB, RoyoBordonada MÁ. Frequency of family meals and childhood overweight: A systematic review. Pediatr Obes. 2013;8(1):e1-e13.

13. Adamson AJ, Baranowski T. Developing technological solutions for dietary assessment in children and young people. J Hum Nutr Diet. 2014;27(suppl 1):1-4.

14. Ahrens W, Siani A, Adan R, et al. Cohort profile: The transition from childhood to adolescence in European children-how I.Family extends the IDEFICS cohort. Int J Epidemiol. 2017;46(5):1394-1395.

15. Hebestreit A, Wolters M, Jilani H, Eiben G, Pala V. Web-based 24hour dietary recall: The SACANA program. In: Baumann K, Lissner L, Pigeot I, Ahrens W, eds. Instruments for Health Surveys in Children and Adolescents. New York, NY: Springer Verlag; 2018.

16. Börnhorst C, Bel-Serrat S, Pigeot I, et al. Validity of 24-h recalls in (pre-) school aged children: Comparison of proxy-reported energy intakes with measured energy expenditure. Clin Nutr. 2014;33(1):79-84. 
17. Ahrens W, Bammann K, Siani A, et al. The IDEFICS cohort: Design, characteristics and participation in the baseline survey. Int J Obes (Lond). 2011;35(suppl 1):S3-S15.

18. Hebestreit A, Intemann T, Siani A, et al. Dietary patterns of European children and their parents in association with family food environment: Results from the I.Family study. Nutrients. 2017;9(2):126.

19. Börnhorst C, Huybrechts I, Hebestreit A, et al. Usual energy and macronutrient intakes in 2-9-year-old European children. Int J Obes. 2014;38(suppl):S115-S123.

20. Börnhorst C, Huybrechts I, Ahrens W, et al. Prevalence and determinants of misreporting among European children in proxyreported 24 h dietary recalls. Br J Nutr. 2013;109(7):1257-1265.

21. Hebestreit A, Barba G, De Henauw S, et al. Cross-sectional and longitudinal associations between energy intake and BMI $z$ score in European children. Int $J$ Behav Nutr Phys Act. 2016;13(1):23.

22. Schofield WN. Predicting basal metabolic rate, new standards and review of previous work. Hum Nutr Clin Nutr. 1985;39(suppl 1):5-41.

23. Cole TJ, Lobstein T. Extended international (IOTF) body mass index cut-offs for thinness, overweight and obesity. Pediatr Obes. 2012;7(4):284-294.

24. Serra-Majem L, Frost Andersen L, Henríque-Sánchez P, et al. Evaluating the quality of dietary intake validation studies. $\mathrm{Br} J$ Nutr. 2009;102(suppl 1):S3.

25. D'Agostino RB, Belanger A. A suggestion for using powerful and informative tests of normality. Am Stat. 1990;44(4):316.
26. Mann HB, Whitney DR. On a test of whether one of two random variables is stochastically larger than the other. Ann Math Stat. 1947;18(1):50-60.

27. Wilcoxon F. Individual comparisons by ranking methods. Biometrics Bull. 1945;1(6):80,

28. Goldberg GR, Black AE, Jebb SA, et al. Critical evaluation of energy intake data using fundamental principles of energy physiology: 1. Derivation of cut-off limits to identify under-recording. Eur J Clin Nutr. 1991;45(12):569-581.

29. Lioret S, Touvier M, Balin M, et al. Characteristics of energy underreporting in children and adolescents. Br J Nutr. 2011;105(11): 1671-1680.

30. Sichert-Hellert W, Kersting M, Manz F, Schöch G. Energy intake of children and adolescents aged 1-18 years: Nutrition survey versus recommendation. Bibl Nutr Dieta. 1994;(51):45-48.

31. Holm S. A simple sequentially rejective multiple test procedure Scand J Stat. 1979;6:65-70.

32. Stata Statistical Software. Release 14. College Station, TX: StataCorp LLC; 2015.

33. Livingstone MBE, Robson PJ, Wallace JMW. Issues in dietary intake assessment of children and adolescents. Br J Nutr. 2004;92(suppl 2):S213S222.

34. Intemann T, Pigeot I, De Henauw S, et al. Urinary sucrose and fructose to validate self-reported sugar intake in children and adolescents: Results from the I.Family study [published online ahead of print March 6, 2018]. Eur J Nutr. https://doi.org/10.1007/s00394018-1649-6.

\section{AUTHOR INFORMATION}

R. Murtas is a researcher, Epidemiology and Prevention Unit, Fondazione IRCSS Istituto Nazionale dei Tumori, Milan, Italy, and Department of Mathematics and Computer Science, University of Cagliari, Cagliari, Italy. V. Krogh is director and V. Pala is a senior researcher, Epidemiology and Prevention Unit, Fondazione IRCSS Istituto Nazionale dei Tumori, Milan, Italy. T. Intemann is a research associate, Leibniz Institute for Prevention Research and Epidemiology - BIPS, Bremen, Germany, and Institute of Statistics, Bremen University, Bremen, Germany. L. Lissner is a professor, Section for Epidemiology and Social Medicine, Sahlgrenska Academy, University of Gothenburg, Gothenburg, Sweden. G. Eiben is an associate professor, Department of Biomedicine and Public Health, School of Health and Education, University of Skövde, Skövde, Sweden. D. Molnár is a professor, Department of Pediatrics, Medical School, University of Pécs, Pécs, Hungary. L. A. Moreno is a professor, Growth, Exercise, Nutrition, and Development Research Group, University of Zaragoza, Zaragoza, Spain. A. Siani is director of research, Institute of Food Sciences, National Research Council, Avellino, Italy. M. Tornaritis is director, Research and Education Institute of Child Health, Strovolos, Cyprus. T. Veidebaum is a professor, National Institute for Health Development, Tallinn, Estonia. A. Mazur is dean, Medical Faculty, and K. Dereń is a lecturer, Institute of Nursing and Health Sciences, Medical Faculty, both at the University of Rzeszów, Rzeszów, Poland. M. Wolters is a research associate, Leibniz Institute for Prevention Research and Epidemiology - BIPS, Bremen, Germany. W. Ahrens is deputy director and head, Department Epidemiological Methods and Etiologic Research, Leibniz Institute for Prevention Research and Epidemiology - BIPS, Bremen, Germany, and a professor, Institute of Statistics, Bremen University, Bremen, Germany.

Address correspondence to: Rossella Murtas, PhD, Epidemiology and Prevention Unit, Fondazione IRCSS Instituto Nazionale dei Tumori, Via Venezian 1, 20133 Milan, Italy. E-mail: ro.murtas@gmail.com

\section{STATEMENT OF POTENTIAL CONFLICT OF INTEREST}

No potential conflict of interest was reported by the authors.

\section{FUNDING/SUPPORT}

This work was part of the I.Family study [www.ifamilystudy.eu] which was funded by the European Commission within the Seventh RTD Framework Programme, Contract No. 266044 (KBBE 2010-14).

\section{ACKNOWLEDGEMENTS}

This work was done as part of the I.Family Study (http://www.ifamilystudy.eu/). We gratefully acknowledge the financial support of the European Commission within the Seventh RTD Framework Programme Contract No. 266044. We thank the I.Family children and their parents for participating in this extensive examination.

We are grateful for the support from school boards, headmasters and communities. The authors thank Don Ward for helping with the English language writing.

\section{AUTHOR CONTRIBUTIONS}

All authors contributed to the acquisition of the data, revised the article, and approved the final version of the manuscript. V. Pala and V. Krogh conceived the study and participated in its design and coordination, V. Pala and R. Murtas drafted the manuscript, and R. Murtas provided the statistical analysis. 